\title{
Effective global tobacco control in the next decade
}

\author{
Prabhat Jha MD DPhil, Sir George Alleyne MD
}

CMAJ Podcasts: author interview at soundcloud.com/cmajpodcasts/jha-tobacco-control

$\mathrm{I}$ $\mathrm{n}$ the decade since the World Health Organization (WHO) adopted the Framework Convention on Tobacco Control, more than 170 countries have signed the agreement. ${ }^{1}$ The framework, and its specific protocols, has mobilized nearly every country to control tobacco more stringently and to report on their progress. However, still more needs to be done to implement all of its provisions. Here, we review progress on global tobacco control and discuss how greater reductions in consumption could be achieved in the next decade.

Recent summaries of epidemiologic evidence showed that, among both men and women, the 21 st century risk of death to people who smoke regularly is threefold higher than the risk among those who do not smoke, ${ }^{2}$ equating to a loss of one decade of life or more. ${ }^{3}$ However, the benefits of quitting smoking manifest quickly in contrast to the slow accumulation of the hazards. In particular, those who quit smoking by 40 years of age avoid about $90 \%$ of the increased risk of death of continuing to smoke. ${ }^{3}$ In Canada, there are more than 1 million more former smokers than just a decade ago. Smoking cessation is common in Canada, as it is among adults in other high-income countries. ${ }^{3-5}$ However, due in large part to the activities of the tobacco industry, cessation remains uncommon in most lowand middle-income countries, where most people who smoke now live. ${ }^{4}$

The WHO has recommended a $30 \%$ reduction in smoking prevalence by 2025, which would save about 200 million lives by the end of the 21 st century among current and future smokers. ${ }^{3}$ The only plausible way to reduce smoking to this extent would be to triple tobacco excise taxes in most low- and middle-income countries. Estimates suggest that tripling excise tax would double the retail price of tobacco products and reduce consumption by about $40 \%$ in these nations. ${ }^{3,6,7}$ In 2013, the WHO reported that only 28 of these countries had comprehensive policies covering counter advertising, restrictions on public smoking and appropriately high taxes, and that few had made progress on raising taxes. ${ }^{1}$
A strategy commonly employed by multinational and state-owned tobacco companies is to coordinate regular tax briefings to ministries of finance in countries around the world. Their aim is to ensure that tobacco tax increases remain below the rate of income growth so that cigarettes remain affordable. These companies also lobby for different taxes on different cigarettes so that smokers can switch to cheaper brands or shorter lengths. ${ }^{3,6,7}$ An example of smart taxation was the late Canadian Finance Minister Jim Flaherty's addition of about 40 cents per pack of cigarettes in January 2014 , along with the allocation of $\$ 100$ million to tax authorities and police to counter smuggling, which may be abetted by the industry. ${ }^{7}$ If fully implemented, these measures will save about 25000 lives among the cohort of Canadian smokers alive today. ${ }^{8}$

Nonprice interventions, such as banning advertising, are unlikely to meet the WHO's goal but do broaden political support for tobacco control. Many young American women took up smoking in the 1960s and 1970s due in part to aggressive advertising (the "Virginia Slims" epidemic). Advertising bans or restrictions are one reason why young Chinese and Indian women have not yet done so. ${ }^{4}$ Australia has adopted plain packaging, which other countries, including Canada, should adopt. ${ }^{9}$ In addition, simple mea-

\section{KEY POINTS}

- Prolonged smoking results in a loss of one decade of life, but quitting by 40 years of age - preferably earlier - avoids $90 \%$ of the excess risk of continued smoking.

- Every metric tonne of tobacco produces 1 million cigarettes and causes 1 death; worldwide, 6 trillion cigarettes were consumed last year, suggesting that about 6 million deaths will eventually occur.

- A tripling of excise taxes in most countries is the only plausible way to reduce consumption by $30 \%$ by 2025 , as recommended by the World Health Organization (WHO).

- Countering the strategies of the tobacco industry could enable higher taxes and stronger tobacco control in the next decade, saving millions of lives.

- The WHO's Framework Convention on Tobacco Control, now a decade old, is an important global treaty, which now needs effective implementation in the next decade to meaningfully reduce consumption. 
sures such as questions on past smoking status, death certificates or verbal autopsies may enable low-cost monitoring of the consequences of tobacco use in many populations.

The WHO estimates that global annual cigarette sales have risen from 5 million to 6 trillion sticks in the last 25 years - a crude estimate suggests that one metric tonne of tobacco produces about one million cigarettes and causes one death. ${ }^{3}$ China, a high consumer of cigarettes, has seen cigarette production increase by $40 \%$ since $2000{ }^{1,7}$ The global tobacco industry gains annual profits of about $\$ 50$ billion $^{3,7}$ - about $\$ 10000$ per tobacco death — providing it with ample funding for strategic lobbying and marketing efforts, which include gaining access to countries' finance officials and funding research on optimal cigarette pricing. The industry's elaborate efforts at interference with tobacco control legislation have been wonderfully and accurately summarized by comedian John Oliver. ${ }^{10}$ Serious global tobacco control must counter these strategies directly.

Canada has a comparative advantage in data sciences; together with other high-income countries, we might help less developed countries to collate accessible and independent data on sales, revenue and smuggling as a basis for rational tobacco tax policy. Finance officials should be encouraged by the International Monetary Fund and World Bank to refuse any visits or advice from tobacco lobbyists, as health officials are recommended to do by the WHO. Other countries could follow the examples set by the Philippines, Mexico and Uruguay; these countries paired expert taxation advice with local political champions to enable large tax increases. ${ }^{3,6}$ South Africa raised taxes in the last decade and has curbed consumption per adult by half., ${ }^{3,11}$ Canadian support helped to raise tobacco taxes in at least one Caribbean country. ${ }^{12}$
The Framework Convention on Tobacco Control is a great achievement in global health. Now is the time to take stronger steps to implement its important provisions. If we do, we might expect to achieve unprecedented numbers of lives saved in the next few decades of the 21st century.

\section{References}

1. WHO report on the global tobacco epidemic, 2013: enforcing bans on tobacco advertising, promotion and sponsorship. Geneva: World Health Organization; 2013.

2. Pirie K, Peto R, Reeves GK, et al. The 21 st century hazards of smoking and benefits of stopping: a prospective study of one million women in the UK. Lancet 2013;381:133-41.

3. Jha P, Peto R. Global effects of smoking, of quitting, and of taxing tobacco. N Engl J Med 2014;370:60-8.

4. Global Tobacco Surveillance System Data (GTSSData). Atlanta: US Centers for Disease Control and Prevention. Available: http://nccd.cdc.gov/gtssdata/Ancillary/DataReports.aspx ?CAID=3 (accessed 2015 Feb. 25)

5. Canadian Tobacco Use Monitoring survey. Ottawa: Health Canada; 2012. Available: www.hc-sc.gc.ca/hc-ps/tobac-tabac/research -recherche/stat/ctums-esutc 2012-eng.php (accessed 2015 Feb. 25).

6. Jha P, MacLennan M, Yurekli A, et al. Global tobacco control. In: Gelband H, Jha P, Sankarnaryanan R, et al., editors. Cancer - disease control priorities. World Bank and Oxford University Press; 2015.

7. WHO technical manual on tobacco tax administration. Geneva: World Health Organization; 2010.

8. Jha P. Tax hike on tobacco could save 25000 lives. The Star [Toronto] 2014; Feb. 25. Available: www.thestar.com/opinion/ commentary/2014/02/25/tax_hike_on_tobacco_could_save_25000 lives.html (accessed 2015 Feb. 25).

9. Wakefield MA, Hayes L, Durkin S, et al. Introduction effects of the Australian plain packaging policy on adult smokers: a cross-sectional study. BMJ Open 2013;3:e003175.

10. Tobacco. Last Week Tonight with John Oliver (HBO) 2015 Feb. 15. Available: www.youtube.com/watch? $\mathrm{v}=6 \mathrm{UsHHOCH} 4 \mathrm{q} 8$ (accessed 2015 Feb. 25).

11. Van Walbeek CP. Industry responses to the tobacco excise tax increases in South Africa. S Afr J Econ 2006;74:110-22.

12. Manning P. 2006-2007 Budget speech [presented in the House of Representatives 2006 Oct. 4]. Trinidad and Tobago News. 2006 Oct. 7. Available: www.trinidadandtobagonews.com/ blog/?p=90 (accessed 2015 Feb. 25).

Affiliations: Centre for Global Health Research, St. Michael's Hospital and Dalla Lana School of Public Health (Jha), University of Toronto, Toronto, Ont.; Pan American Health Organization (Alleyne), Washington, DC

Contributors: Both of the authors contributed equally to the concept, writing and revising of the article. Both of the authors approved the final version to be published. Prabhat Jha is guarantor of the work. 